\title{
Pregnancy in women with thalassemia: challenges and solutions
}

\author{
This article was published in the following Dove Press journal: \\ International Journal of Women's Health \\ 8 September 2016 \\ Number of times this article has been viewed
}

\section{George Petrakos \\ Panagiotis Andriopoulos \\ Maria Tsironi \\ Department of Nursing, University of Peloponnese, Sparta, Greece}

\begin{abstract}
Advances in treatment of thalassemia have led to the aging of thalassemic patients, and consequently concern about successful reproductive outcome is augmented. Although women with thalassemia intermedia only were considered competent of achieving pregnancy, case series reveal the willingness of both thalassemia major and thalassemia intermedia women to have a family. Pregnancy in general is characterized by dynamic multiple-system changes and increased susceptibility to oxidative stress, while homozygous, transfusion-dependent, $\beta$-thalassemia patients manifest cardiac, hepatic, endocrine, and metabolic disorders attributable to chronic anoxia and iron overload and thalassemia intermedia, usually nontransfused, is associated with augmented risk of thromboembolic events. Pregnancy in thalassemia should be considered a high risk for both mother and fetus, and favorable outcomes are the result of continuous preconception, antenatal, and postpartum assessment and management by a team of thalassemia experts.
\end{abstract}

Keywords: thalassemia, pregnancy, chelation, transfusion, iron

\section{Introduction}

Hemoglobinopathies are among the most common inherited diseases: approximately $7 \%$ of the global population is a carrier, and 300,000-500,000 children are born with a severe hemoglobin disorder annually. ${ }^{1}$ They are classified according to the impaired globin chains and whether this disorder leads to reduced production of a normal chain or an abnormal tertiary structure of globin chains. The precise structure of the globin chains is coded by genes of chromosomes 16 (the $\alpha$-gene cluster, comprising the $\alpha$-and $\zeta$-globin chains) and 11 (the $\beta$-gene cluster, comprising the globin chains $\gamma, \varepsilon, \beta$, and $\delta$ ). Hemoglobin must have the correct structure and be trimmed in such a way that the number of $\alpha$-chains precisely matches that of the $\beta$-chains. In adulthood, hemoglobin consists of approximately $98 \% \mathrm{HbA}\left(\alpha_{2} \beta_{2}\right)$, less than $3 \% \mathrm{HbA}_{2}\left(\alpha_{2} \delta_{2}\right)$, and traces of $\mathrm{HbF}\left(\alpha_{2} \gamma_{2}\right)$. The term "thalassemia" refers to hemoglobinopathies characterized by partly or completely suppressed synthesis of one of the two types of polypeptide chains ( $\alpha$ or $\beta)$ as a result of missense/nonsense mutations (single-base substitutions) or frameshift mutations of the genes controlling the structure of the hemoglobin-protein chains in one or both "allelic" globin genes, providing decreased hemoglobin concentration, microcytosis, and anemia. Depending on the genes affected, the resulting defect, and the corresponding effect on the globin chain, several types of thalassemia have been described, the most common types of clinical importance being $\alpha$-, $\beta / \delta$-, and $\beta$-thalassemia. ${ }^{2-5}$

\section{Genetic basis and pathophysiology of thalassemias}

$\alpha$-Thalassemia is the most common inherited disorder of hemoglobin, is characterized by reduced or suppressed production of $\alpha$-globin chains, and occurs at particularly high 
frequency in populations from sub-Saharan Africa through the Mediterranean region and Middle East, to the Indian subcontinent and East and Southeast Asia. ${ }^{1}$ Almost $5 \%$ of the world's population are carriers, and approximately 1,000,000 patients are affected by various $\alpha$-thalassemia syndromes worldwide. ${ }^{6,7}$ The $\alpha$-globin chain synthesis begins in fetal life. The responsible genes - four in total - are situated in two genetic loci in chromosome 16. Gene deletion or less commonly mutation results in $\alpha$-thalassemia, and phenotype depends on the affected gene number. When all four genes are affected $(-/-\mid-/-)$ in homozygous $\alpha$-thalassemia, fetal synthesis of $\alpha$-chains is impossible, leading to an excess of $\gamma$-chains and forming the unstable Bart's hemoglobin $\left(\gamma_{4}\right)$, which is incapable of oxygen exchange. The affected fetuses sustain severe anemia, cardiomegaly, and hydrops fetalis, and ultimately intrauterine or neonatal death. When three genes are affected $\left(\alpha^{-/ /-}\right), \alpha$-chain synthesis is restricted to a minimum. Therefore, $\beta$-chains that exist in excess form the unstable $\mathrm{HbH}\left(\beta_{4}\right)$. $\mathrm{HbH}$ disease has a phenotypic variability based on mutation type, ranging from mild anemia (deletions on chromosome 16) to a transfusion-dependent one. ${ }^{8}$ The existence of two $\alpha$-genes ( $\alpha$-thalassemia trait) is expressed as a mild hypochromic microcytic anemia. Globin synthesis is still unbalanced, leading to hemolysis and iron overload. In $\alpha^{0}$-thalassemia, the two deleted genes belong to the same allele $(-/-\mid \alpha / \alpha)$, and this is prevalent among Asian and Eastern Mediterranean populations, while in $\alpha^{+}$-thalassemia, prevalent among African people, the deleted genes belong to different homologous chromosomes. In "silent" carriers, only one $\alpha$-gene is affected $(\alpha /-\mid \alpha / \alpha)$, and the three functional remaining ones are capable of normal hemoglobin production. ${ }^{9}$

$\beta$-Thalassemia is extremely heterogeneous in terms both of genotype and phenotype, depending on the nature of $\beta$-gene mutation and the extent of impairment in $\beta$-globin chain production. As a rule, heterozygous carriers of $\beta$-thalassemia (one affected allele), are asymptomatic, and only altered laboratory values (low, normal, or slightly subnormal hemoglobin levels, slightly low mean cellular hemoglobin, low mean cell volume, low $\beta$ : $\alpha$-globin chain ratio on biosynthesis, $\mathrm{HbA}_{2} \geq 3.5 \%$ ) are observed. ${ }^{10}$

In contrast, inheritance of two defective $\beta$-globin genes results in a wide phenotype spectrum, ranging from transfusion-dependent (thalassemia major [TM]) to mild or moderate anemia (thalassemia intermedia [TI]). $\beta^{0}$ refers to the complete absence of production of $\beta$-globin on the affected allele, $\beta^{+}$refers to alleles with some residual production of $\beta$-globin, and $\beta^{++}$to a very mild reduction in $\beta$-globin production. More than 200 thalassemic mutations have been reported. TI mutations in both parental genes lead to a moderate reduction in $\beta$-globin production. TI represents up to a quarter of $\beta$-thalassemia patients with a wide spectrum of genotypes and a clinical phenotype ranging between transfusion-dependent thalassemia and the asymptomatic carrier state. Patients have in general later clinical onset, milder anemia not requiring transfusions for survival during the first few years of life, and quality of life is not severely impaired, but the clinical course of the disease, if remaining untreated, is complicated by the multiple effects of chronic hemolytic anemia and the consequent tissue hypoxia, as well as by their compensatory reactions, including increased erythropoiesis with bone marrow expansion and increased intestinal iron absorption. ${ }^{11,12}$

$\beta$-TM or Cooley's anemia $\left(\beta^{0} / \beta^{0}\right.$ or $\left.\beta^{0} / \beta^{+}\right)$is characterized by severe hypochromic microcytic anemia, which becomes symptomatic at infancy or early childhood and is apparently transfusion-dependent. The globin chain-synthesis reduction leads to an unbalanced $\beta / \alpha$-globin chain production, where the chains in abundance precipitate, forming erythrocyte inclusions. Pathophysiology is characterized by damaged red blood cells, hemolysis, and erythroid-precursor release in the peripheral circulation, due to ineffective erythropoiesis. The phenotype includes anemia, bone marrow expansion, skeletal deformities, growth restriction, and late sexual maturity. ${ }^{11,12}$

As far as it concerns the $\beta$-thalassemia population, advances in care by optimal blood transfusion and ironchelation therapy have improved patient survival into adulthood, as well as quality of life. ${ }^{13}$ Consequently, concern about favorable reproductive outcome has increased, as a result of patients' desire to create their own family. Although women with TI were considered competent of achieving pregnancy ${ }^{14}$ after the first observations in the mid-1960s, an increasing number of spontaneous or assisted reproductive technology conceptions in both TI and TM have been reported. ${ }^{15-24}$

This article attempts to review available evidence documenting pregnancy in thalassemia, focusing mainly on $\beta$-thalassemia and its appropriate follow-up, as it can be a high-risk state for both mother and fetus, and close counseling and monitoring starting from the preconception stage is mandatory.

\section{Fertility in $\beta$-thalassemia}

Hypogonadotropic hypogonadism (HH) is the most frequent endocrinopathy in transfused patients with TM: 51\%-66\% of thalassemic patients with marked hemosiderosis are predisposed to develop pubertal failure, sexual dysfunction, 
infertility, and short stature. ${ }^{25,26}$ Iron accumulation in the anterior pituitary gland, a tissue with high levels of transferrin receptor, results in free radical oxidative stress, impairing gonadotropins and growth-hormone secretion. ${ }^{27}$ Furthermore, thalassemics may also suffer from iron accumulation in the ovaries or testes, and oxidative stress may be developed there, when imbalance between the generation of reactive oxygen species and the scavenging capacity of antioxidants in the reproductive tract is present. ${ }^{28}$ According to the literature, reactive oxygen species may have an important regulatory role through various signal-transduction pathways in the normal functioning of the reproductive system and in female infertility, affecting multiple physiological processes from oocyte maturation to fertilization, embryo development, and pregnancy, ${ }^{29}$ while recent studies have shown significant acute changes in the hormonal environment and sperm parameters of iron-overloaded patients. ${ }^{30-32}$ Susceptibility to HH development seems to be associated with genotype, as patients with severe underlying molecular defects have a greater rate of iron loading and probably a different vulnerability to free radical damage. ${ }^{33,34}$ Furthermore, HH is related to iron toxicity in adipose tissue, impairing and changing the physiological role of leptin - acting as a permissive signal allowing puberty - in sexual maturation and fertility. ${ }^{35,36}$ The possible role of liver dysfunction and the presence of other endocrinopathies, such as diabetes or hypothyroidism, should not be underestimated when assessing fertility, ${ }^{37}$ while chronic hypoxia seems to have a crucial role, as studies have revealed decreased gonadotropin secretion within even 2 days of arrival at moderate altitude, enhancing the role of chronic anemia. ${ }^{38}$

Singer et al suggested that ovarian reserve is preserved in the majority of TM patients less than 30-35 years old, despite a low follicle count and reduced ovarian volume, and that anti-Müllerian hormone could be used as a sensitive marker for ovarian reserve independently of gonadotropin effect correlated with non-transferrin-bound iron, suggesting a role of labile iron in the pathogenesis of decreased reproductive capacity. ${ }^{39}$ Pulsatile gonadotropin-releasing hormone infusion for ovulation induction is only possible at the early stage of hypothalamic-pituitary damage, but as the majority of patients with $\mathrm{HH}$ are nonpulsatile with functional gonads, they are more likely to benefit from human chorionic gonadotropin/ human menopausal gonadotropin therapy, which has an $80 \%$ success rate. ${ }^{40}$ Ovulation induction should only be undertaken by a specialist reproductive team, according to Human Fertilisation and Embryology Authority (HFEA) guidelines ${ }^{41}$ keeping in mind and making women aware of the risk of hyperstimulation syndrome, multiple pregnancy, ectopic pregnancy, and miscarriage. Around $1 \%-2 \%$ of inducted ovulation cases develop severe hyperstimulation syndrome causing fluid retention with bloating, breathlessness, and nausea, resulting in abdominal pain, vomiting, dyspnea, and rapid weight gain, while the most severe cases have to be hospitalized because of hypovolemic shock, renal and/ or respiratory insufficiency, and arterial thromboembolism. ${ }^{42}$ Protocols for thalassemic women usually involve standard regimes. Patients with endometrial or fallopian tube damage respond better to in vitro fertilization (IVF) programs.

Spermatogenesis in thalassemic males is more difficult, with a success rate of $10 \%-15 \%$ in moderate to severely ironloaded patients. ${ }^{40}$ The induction process must be undertaken according to HFEA guidelines, with an emphasis on consent and counseling. ${ }^{41}$ Micromanipulation techniques, such as intracytoplasmic sperm injection (ICSI), have improved conception rates, even in oligoasthenospermic patients. Sperm should be cryopreserved in all subjects unless azoospermic to preserve fertility and the chance of conception better. However, thalassemic patients with low sperm concentrations are more likely to have a higher degree of defective chromatin packaging, while the negative association between ferritin levels and abnormal sperm morphology suggests a possible detrimental effect on spermatogenesis by the iron chelators. ${ }^{43}$ Thalassemic patients considered for assisted conception procedures should be counseled accordingly, as mutagenic risk in these individuals, especially after ICSI, where the natural protective barrier against gamete selection during fertilization is lost, seems to be high. ${ }^{44}$

\section{Prepregnancy planning}

Pregnancy planning is essential in both spontaneous and assisted reproductive technology conceptions. Cardiac and liver function, infection control, screening for endocrinological abnormalities, and medication review should be considered regarding females, while both partners should be checked for hemoglobinopathies. ${ }^{45}$

\section{Screening for thalassemias - genetic counseling}

Identifying high-risk populations for thalassemia is the main step for reducing incidence. Screening programs may differ throughout the world, depending on population needs, culture, and/or ethics, and although antenatal diagnosis remains a personal choice, policies are focused on education and counseling. ${ }^{46,47}$ In Greece, where carriers account for 7.5\% of the general population, such a program has been in place since the 1970s, raising awareness and drawing attention to this 
inherited disease. ${ }^{48,49}$ Traditionally, thalassemia was known of higher prevalence in populations of the Middle East, Eastern Mediterranean, India, and Africa, but freedom of movement and subsequent immigration of populations, as well as interethnic mixing, has altered trends. However, according to Hussein et al, there is a lack of randomized trials of preconception genetic risk assessment, and evidence for current policy recommendations is limited to nonrandomized studies. ${ }^{50}$

Hemoglobin electrophoresis remains the gold standard for the diagnosis and classification of thalassemia. Quantitative evaluation of $\mathrm{HbA}_{2}$ can be made by either electrophoresis or by high-pressure liquid chromatography. Nevertheless, the latter has the additional advantage of quantifying $\mathrm{HbF}$ at the same time. Carriers of the $\beta$-thalassemia trait demonstrate increased values of $\mathrm{HbA}_{2}$ and $\mathrm{HbF} .{ }^{51-53}$

Where both parents are carriers of the same trait $(\alpha-\alpha$ or $\beta-\beta$ couple), genetic counseling should be performed so as to achieve prenatal diagnosis. The couple should be informed of the possibility ( $25 \%$ ) of a TM fetus. The diagnosis is made either by chorionic villus sampling or by amniocentesis. Chorionic villus sampling has some advantages, as it can set the diagnosis earlier during the first trimester (11th week), more DNA is obtained by placental biopsy, and it is perhaps safer to penetrate the placenta than the amniotic cavity. On the contrary, amniocentesis has the drawback of being feasible only after the 16th week. The risk of miscarriage does not differ between these invasive procedures, and is estimated to be less than $1 \% .^{54-59}$

When both parents suffer from a certain hemoglobinopathy, use of donor gametes screened for hemoglobinopathies preferably donor sperm, as sperm can be more easily available from sperm banks - seems to be the ideal option, while adoption always remain an alternative. If the partner of a homozygous parent is heterozygous, preimplantation genetic diagnosis should be proposed. This involves IVF/ICSI, embryo biopsy, and transfer of healthy embryos. Preimplantation genetic diagnosis can be performed at either the eight-cell stage (cleavage stage) on day 3 after fertilization or at the blastocyst stage on day 5 by biopsy of the trophoblast cells. Cleavage-stage biopsy is often preferred, as it results in more viable blastocysts and offers more time for genetic testing before embryo transfer. Polymerase chain-reaction techniques (nested, multiplex, fluorescent) have overcome limitations of cleavage-stage biopsy with regard to the small number of cells available for assessment. ${ }^{60-67}$

\section{Cardiac assessment}

Pregnancy-induced cardiovascular changes are the result of the increased metabolic demands of both mother and fetus, and are clinically presented by signs and symptoms resembling heart failure. ${ }^{68}$ During pregnancy, the heart undergoes important structural changes, such as transient left ventricular hypertrophy, in order to support the demanded increase in functional load, which is as great as $25 \%-30 \%$. In general, pregnant women tolerate valvular incompetence and uncomplicated left-to-right shunts better than stenosis. Upward displacement of the diaphragm by the enlarging uterus causes the heart to shift to the left and anteriorly, so that the apex beat is moved outward and upward. Furthermore, peripartum cardiomyopathy, a rare condition occurring in the last month of pregnancy or during the 5 postpartum months, is a heart disorder with an unpredictable outcome varying from complete recovery, myocardial sequelae, or aggravation, leading to cardiac transplantation or death. Cardiac function should be assessed by a cardiologist and investigated with electrocardiography (ECG), cardiac echo, and 24-hour Holter monitoring of rhythm in terms of symptoms. ${ }^{68}$

Despite the increased functional cardiac load during gestation and labor, healthy women do not have cardiac reserve impairment. In contrary, the increased functional load on the heart may cause ventricular failure and pulmonary edema to pregnant women with established or misdiagnosed heart disease and low cardiac reserve. Heart disorders are responsible for about $10 \%$ of maternal obstetric deaths, and congenital heart disease may be underestimated. Premature labor can be induced by heart failure, while the risk of maternal or fetal death is strongly associated with maternal New York Heart Association functional classification. Women with certain high-risk disorders (eg, pulmonary hypertension, severe valvular disorders, prior postpartum cardiomyopathy) should be discouraged from pregnancy, as there is high correlation with considerable morbidity and mortality rates. ${ }^{23}$

Cardiac complications remain the leading cause of death for the thalassemic population. Apart from cardiac iron overload due to regular blood transfusions and delayed or inadequate chelation therapy, thalassemic patients have a greater intestinal iron-absorption capacity than normal individuals, resulting from paradoxical hepcidin suppression from dyserythropoiesis. ${ }^{69}$ Iron stored in cells, including myocytes, in the form of ferritin, hemosiderin, and free iron, is referred as labile cellular iron. The latter form stimulates the formation of free radicals, provoking cellular injury due to peroxidation damage of membrane lipids and proteins. ${ }^{70}$ In thalassemic women, iron overload increases the oxidative stress of pregnancy, which peaks by the second trimester of gestation, and can induce great damage to the fetus. ${ }^{71}$ During pregnancy, basal oxygen consumption is increased and changes in energy substrate use by different organs are 
revealed, including the fetoplacental unit. As the initially hypoxic placenta matures and its vascularization develops, it becomes rich in mitochondria, producing locally free radicals and increasing free iron. The impaired function of the mitochondrial respiratory chain affects the heart muscle, leading to decreased cardiac muscular contractility and congestive heart-failure development. In TM, the impaired heart is obliged to maintain a high output through a rigid vascular bed induced by chronic hemolysis, subjected to a continuous state of both volume and pressure overload, rendering the left ventricle more susceptible to decompensation, ${ }^{72}$ while the gradually increasing pulmonary vascular resistance seems to lead to the development of pulmonary hypertension, which readily precipitates right-ventricular failure. ${ }^{73}$

Thalassemic pregnant women with normal resting cardiac performance and intensive pregestational chelation therapy usually carry out gestation and delivery successfully. ${ }^{16-18,22,74}$ However, it is rather uncertain whether a woman with marginally impaired cardiac performance or with myocardial hemosiderosis, present even in well-chelated patients, will work out the pregnancy stress and the referred hemodynamic changes. Cardiac magnetic resonance imaging (MRI) has been proven of high value with regard to preconception cardiac management. It can accurately define iron overload - underestimated when using only ferritin values or echocardiography - and guide and if needed intensify chelation therapy. ${ }^{75,76}$ The ultimate target is $T_{2}{ }^{*} \geq 20 \mathrm{~ms}$ if possible; however, successful pregnancies have been achieved with lower levels. $T_{2}{ }^{*}$ levels $\leq 10 \mathrm{~ms}$ should draw attention, as they suggest a high risk of developing heart failure. ${ }^{77}$ Therefore, all women planning a pregnancy should be assessed by a thalassemia-specialist cardiologist by ECG, cardiac echo study, 24-hour Holter monitoring of rhythm, and mainly by MRI $T_{2}{ }^{*}$ measurement. ${ }^{78}$

\section{Infections}

Gestational estrogen levels are elevated, leading to reduction of total immune function and an augmented infection risk. Therefore, clinical as well as silent infections have higher prevalence during pregnancy, while about $18 \%$ of apparently normal gestations and 33\% of premature deliveries present with evidence of chorioamnionitis. ${ }^{79}$ In thalassemia, iron overload is considered to be the main etiologic factor that can disturb the immune balance, as the inflammatory processes are exacerbated by free intracellular iron, increased initially by inflammatory cytokines (IL-1 $\beta$ ) that possibly release free iron from ferritin or mitochondria and then increase ferritin synthesis. ${ }^{80,81}$ Apart from this, transfusion-transmitted viral infections can be a great risk. All women should be tested for hepatitis B virus (HBV), HCV, HIV, cytomegalovirus, and human parvovirus B19, particularly by the age of pregnancy, as infection with multiple strains and reactivation of existing cytomegalovirus strains are possible events in thalassemics. ${ }^{82}$ HBV and rubella vaccinations - although the latter virus is not particularly connected to thalassemia, but is a known teratogen - are strongly advised, and should be checked before conception. Splenectomized women should take penicillin prophylaxis.$^{83} \mathrm{HIV}$-positive women should be advised to commence highly active antiretroviral therapy, deliver by cesarean section (CS) and avoid breast-feeding, whereas HCV-positive women should start appropriate therapy so as to eliminate HCV RNA. ${ }^{84}$

\section{Liver function}

During pregnancy, impairment of liver function can be expected, and may present with subtle findings. Aminotransferases might be slightly elevated, warning of life-threatening processes, such as acute fatty liver of pregnancy or HELLP (hemolysis, elevated liver enzyme levels, low platelet count) syndrome ${ }^{85}$ Thalassemic women are prone to cholelithiasis due to hemolytic anemia and subsequent cholecystitis, while impaired liver function due to iron overload may be present. Preconception liver and biliary tract ultrasound assessment should be performed at a minimum to detect liver cirrhosis, fibrosis, and cholelithiasis, and cholecystectomy should be considered before impregnation. Reduced survival in thalassemia is associated with liver iron concentration above $15 \mathrm{mg} / \mathrm{g}$ dry weight. ${ }^{14,86}$ MRI of hepatic iron content using $R_{2}$ and $R_{2}{ }^{*}$ techniques provide accurate and reproducible quantitation of liver iron concentration in thalassemia, and in contrast to liver biopsy, which is invasive and associated with risks, including bleeding and procedure-related pain, is generally more acceptable to patients. ${ }^{87,88} \mathrm{~A}$ target liver iron concentration of less than $7 \mathrm{mg} / \mathrm{g}$ dry weight is recommended prior to conception, and in cases of target excess, intensive preconception chelation should be proposed ${ }^{89}$

\section{Endocrine complications}

Apart from $\mathrm{HH}$, other glands may be affected by tissue hemochromatosis. Diabetes mellitus is frequently diagnosed, resulting from insulin resistance, pancreatic iron overload, genetic factors, and autoimmunity..$^{90}$ Those women should be referred to an endocrinologist and have serum fructosamine concentrations kept below $300 \mathrm{nmol} / \mathrm{L}$ for at least 3 months before conception..$^{91}$ Coexistence of thalassemia and diabetes is an indication of monthly assessment of serum fructosamine concentration. Thyroid function should be assessed and treated before pregnancy, in order to avoid 
gestational complications (maternal and perinatal morbidity and mortality), and determined periodically throughout pregnancy. $^{92}$

Osteoporosis and bone deformity are also present in thalassemic patients, as a result of parathyroid dysfunction, hypogonadism, chelation of calcium by iron-chelation drugs, and vitamin $\mathrm{D}$ deficiency. Bone mineral density should be assessed by dual-energy X-ray absorptiometry of the spine or hip for all women with osteopenia or osteoporosis, and supplements should be offered in order to optimize serum vitamin D concentrations. ${ }^{93,94}$

\section{Medication review}

Before pregnancy is actively contemplated or ovulation induced, potentially teratogenic medication needs to be reviewed, including oral hypoglycemic agents, bisphosphonates, and ACE inhibitors. Women on oral chelators (deferasirox $[\mathrm{DFX}]$ or deferiprone) are recommended to switch to desferrioxamine [DFO] prior to induction of ovulation/ spermatogenesis. ${ }^{45}$ Medications that should be discontinued at least 6 months prior to fertility treatment include interferon, ribavirin, and hydroxyurea. Hypothyroid patients receiving thyroid-replacement therapy should receive increased doses to ensure they are euthyroid.

\section{Antepartum management}

Pregnant women must be reviewed monthly until the 28th gestational week and every 2 weeks thereafter. Preterm birth related to poor maternal condition, fetal distress, multiplegestation pregnancies, and placental ischemic disease can complicate gestation. Other commonly met obstetric complications include gestational hypertension, gestational diabetes, placental abruption, urinary tract infection, and renal and gallbladder stones. ${ }^{22,24,55}$ Women should be screened for gestational diabetes at 16 weeks, and if normal this should be repeated again at 28 weeks. Furthermore, heterozygous thalassemic pregnant women in ethnic groups with high diabetes mellitus incidence should be screened for gestational diabetes. ${ }^{90,91,95,96}$ Splenomegaly can interfere with the enlargement of the uterus and can be complicated by hypersplenism, necessitating splenectomy during gestation or after delivery. ${ }^{15}$

\section{Maternal transfusion}

Anemia in women with thalassemia deteriorates during pregnancy; however, a proportion of them can remain undiagnosed without screening, as anemia can be of a mild degree or absent. Therefore, their pregnancy will usually be uneventful and normally completed. ${ }^{97,98}$ Thalassemia per se in combination with gestational anemia (secondary to increased fluid compartment of the body) account partly for different complications of the thalassemic pregnancy, such as fetal intrauterine growth restriction (IUGR) and preterm labor. ${ }^{99,100}$ Most centers transfuse pregnant women aiming to maintain hemoglobin at the preconception goal $(>10 \mathrm{~g} / \mathrm{dL})$ to ensure appropriate fetal growth. ${ }^{15,18,22}$ Despite following this approach, IUGR may be present, suggesting the role of other fetoplacental and maternal factors, while transfusion-acquired red-cell antibodies should be checked prior to pregnancy. ${ }^{101}$

Referring to TI never- or minimally transfused women, when blood transfusion is necessary, extended genotype and antibody screening should be performed and fully phenotyped matched blood given, as the major fear of inaugural blood transfusions during pregnancy is the developing of alloantibodies, which can stimulate anemia aggravation and grow into severe hemolytic anemia obstinate to transfusions, along with viral transmissions, raising the complication rate. The decision to initiate a transfusion regimen is based on the presence of a worsening maternal anemia or evidence of IUGR, and in this case regular transfusions should be considered. The largest case series of TI pregnancies reported IUGR in $22 \%$ of pregnancies. ${ }^{102}$ However, a recent Italian TI case series with trials of random transfusion regimens administered based on total hemoglobin level but also on general and cardiac maternal status and fetal growth showed that most babies were appropriate for gestational age. ${ }^{22}$ In general, nontransfused women with hemoglobin $\geq 8 \mathrm{~g} / \mathrm{dL}$ at the 36 th week of gestation should be advised not to initiate blood transfusions, ${ }^{88}$ and erythropoietin administration could be an alternative. ${ }^{103,104}$

Hemolytic alloantibody and erythrocyte-autoantibody development complicates transfusion therapy in thalassemia patients as the rate of red blood-cell alloimmunization following one single blood-unit transfusion is $1 \%-1.6 \%$, while the rate in patients receiving regular blood transfusions may be as high as $60 \%{ }^{105-107}$ Alloantibodies crossing placenta can cause fetal and/or neonatal hemolytic anemia, making extended genotype and antibody screening necessary before transfusion, and if transfusion is necessary, fully phenotyped matched blood should be given. Referral to a fetal medicine specialist for consideration of invasive treatment should take place if the middle cerebral artery peak systolic velocity - a noninvasive test for fetal anemia - rises above 1.5-fold the median threshold or if there are other signs of fetal anemia. ${ }^{108}$ 


\section{Chelation during pregnancy}

Throughout pregnancy, acceptable levels of maternal hemoglobin should be maintained to minimize hypoxia, but intensive transfusion treatment can aggravate hemosiderosis in patients with a preexisting iron-overload status, elevating oxidative stress and inducing organ failure, whereas women identified with cardiac hemosiderosis or borderline leftventricle function may bear heart complications. ${ }^{109}$ Therefore, the role of chelation during pregnancy should be clarified.

Chelation therapy will reduce iron overload and help free radical scavenging, reducing the inflammatory process, ${ }^{110}$ but DFO fetotoxicity has not yet been definitely assessed. Although animal studies may identify drug teratogenic effects and skeletal anomalies, the large molecular size and charge of DFO makes placenta crossing doubtful. ${ }^{111,112}$ Various case reports describe its use in early pregnancy, ${ }^{21,45,78,113}$ as well as a large case series of $32 \mathrm{TM}$ women chelated with DFO during the second and third trimesters with favorable fetal outcomes..$^{20}$ According to experts, DFO should be avoided during the first trimester, but subcutaneous administration may be considered in the second and third trimesters for patients with a strong indication for treatment. ${ }^{114}$ As to oral chelators, according to experimental models placental transfer of DFX is minimal in rats, ${ }^{115}$ but fetal outcome data in humans are limited to spontaneous pregnancy case reports, ${ }^{116,117}$ and based on the product label DFX use is contraindicated in pregnant women.

During pregnancy, chelation should be restricted for cases where the potential benefit outweighs the potential fetal risk. If a woman describes cardiac symptoms during pregnancy, she should immediately be assessed by a cardiologist with expertise in thalassemia, in order to balance the risks and decide on the need for chelation treatment. ${ }^{78,118,119}$

\section{Pregnancy and thromboembolic events}

Gestation predisposes to hypercoagulation. Venous thromboembolism frequency is as high as 0.76 to 1.72 per 1,000 gestations, while maternal death is caused prominently by pulmonary embolism. ${ }^{120}$ Platelet activation, fibrin generation, and coagulation factors II, VII, VIII, and X are increased, contrary to fibrinolytic activity and free protein $\mathrm{S}$ levels, which are decreased. Additional risk factors for venous thromboembolism during pregnancy and the postpartum period are the reduction in venous flow velocity during gestation, inherited thrombophilias, antiphospholipid syndrome, and previous history of thrombosis. ${ }^{121}$

Thalassemic women have an increased risk for thrombosis, as the disease entity is a chronic hypercoagulable state with high incidence of thromboembolic episodes, especially in TI, with a risk of as high as $29 \%$, especially in splenectomized and nontransfused patients. ${ }^{122-125}$ Inherent red-cell defects that activate endothelial cells, creating a procoagulant state, along with platelet abnormalities, deficiency of coagulation inhibitors, cardiac and liver dysfunction, and hormonal deficiencies, seem to comprise the pathophysiology. ${ }^{125}$ Therefore, frequently transfused patients have lower rates of thromboembolism compared with those who are not. ${ }^{123,125}$

Thrombophylaxis might be essential during pregnancy and the postpartum period in cases of nontransfused TI, splenectomy, or a history of recurrent abortions. ${ }^{126}$ According to recent data, low-dose aspirin, frequently administered to splenectomized $\beta$-thalassemia patients, seems to be effective in preventing preeclampsia, preterm birth, and IUGR in highrisk pregnancies without posing a major safety risk to mothers or fetuses. ${ }^{127}$ Therefore, splenectomized women or those with a serum platelet count above $600 \times 10^{9} / \mathrm{L}$ should begin or continue taking aspirin at a dose of $75 \mathrm{mg} /$ day. Splenectomized women with a platelet count above $600 \times 10^{9} / \mathrm{L}$ should additionally be offered low-molecular-weight heparin. ${ }^{22,126-129}$

\section{Fetal monitoring}

The first ultrasound scan should be performed at the 7th-9th week of gestation, as these women have a high risk of miscarriage and multiple gestations. In addition to first-trimester (11th-14th weeks) and second trimester (18th-21st weeks) scans, serial fetal biometry scans should be performed monthly after the 24th gestational week, focusing on possible IUGR as a result of chronic maternal anemia and other nutritional elements depletion. ${ }^{22,89}$ The percentage of babies with IUGR varies among different studies as spontaneous conceptions, IVF cases, and singleton and multiple pregnancies are encountered. ${ }^{22,33}$ Miscarriage occurs mostly in cases of thalassemia homozygous fetuses or those with severe IUGR. ${ }^{74}$ The reported frequency varies from $9 \%$ to almost $33 \%$, which can be explained by gestations conceived spontaneously and through IVF.

\section{Medication modification}

Women should be advised to modify their lifestyle and diet, avoid smoking and alcohol, and start taking supplements of folic acid, calcium, and vitamin D. Before and throughout pregnancy, as well as during breast-feeding, adequate calcium and vitamin $\mathrm{D}$ intake and bisphosphonate interruption is mandatory, as both are negative calcium-balance states. Especially for thalassemic women, often osteoporotic and vitamin D-deficient, vitamin D levels should be optimized 
before pregnancy and thereafter maintained within the normal range. ${ }^{94}$ Folate demand in pregnancy is normally increased, and all thalassemic women are advised to receive folic acid supplementation at a dose of $5 \mathrm{mg} / \mathrm{day}$, in order to prevent fetal neural tube defects, as well as a significant increase in predelivery hemoglobin level, ${ }^{130}$ and in heterozygous cases to prevent superimposed megaloblastic anaemia. ${ }^{131}$

\section{Intrapartum management}

Time and mode of delivery should be individualized for thalassemia per se, as an uncomplicated disease course should not be considered a proper indication for CS. However, most cases of CS can be attributed to the higher frequency of cephalopelvic disproportion, mainly due to short maternal stature and skeletal deformities combined with normal fetal growth. In case of CS, epidural anesthesia is preferable compared to general anesthesia, as severe maxillofacial deformity in TM patients, especially the older ones, may augment difficulties of intubation. ${ }^{132}$ Under this point of view, it is important to correct osteoporosis where required preconception, as spinal abnormalities associated with TM are relevant to regional blockade. ${ }^{133}$

If vaginal delivery is decided, active management of the third stage of delivery is recommended, as this intervention is supposed to reduce blood loss. ${ }^{134}$ Fetal hypoxia is common during labor, and thus continuous electronic fetal monitoring is recommended. Transfusion-dependent women that are not chelated will have high concentrations of nontransferrin-bound iron in the serum, a toxic iron form, which can cause cardiac dysrhythmias in combination with labor stress. Therefore, intravenous DFO - 2 g over 24 hours - is recommended for the duration of labor. ${ }^{135}$

\section{Postpartum management}

During the postpartum stage, there is a high risk of venous thromboembolism for women with thalassemia, and lowmolecular-weight heparin prophylaxis should be administered in hospital, ${ }^{124,125,136}$ followed by a 7-day postdischarge regimen after vaginal delivery or a 6-week regimen after CS. ${ }^{135}$ Women should be referred to a cardiologist after labor, as postpartum cardiac complications have been confirmed. ${ }^{17,137}$ Finally, they should be encouraged to breast-feed, as it is safe in all cases except for those who are HIV, hepatitis C RNA-positive, and/or HBV surface antigen-positive, because of the risk of transmission via breast milk. Significantly lower rates of breast-feeding maintenance when compared to the general population could be explained by the need to restart chelation therapy with oral agents, both of which are contraindicated during breast-feeding, while postpartum chelation using DFO seems to be safe, as DFO is not orally absorbed. Calcium and vitamin D supplements should be continued during breast-feeding, but bisphosphonates should be resumed after cessation of breast-feeding.

\section{Conclusion}

Advances in chelation treatment along with regular transfusions have introduced a new era for the thalassemic population, increasing the average life span and rendering the perspective of reproductive capacity attainment and creation of a family, a rational goal for patients and a great task for relevant clinicians. Pregnancy in TM and TI should be considered a high-risk pregnancy, although gestation can be completed safely for both mother and fetus as long as pregnant women follow close screening and are referred to thalassemia specialists. However, as different experts suggest, a standard management plan should be applied to this group of pregnant women, ${ }^{138}$ starting with a complete preconception assessment, in order to evaluate and reduce possible risks during pregnancy. Evaluation should include thorough checking for hormonal abnormalities, infectious diseases, liver function, and coagulation status. Women carefully managed and well chelated during preconception usually carry out a successful gestation and labor. Hemoglobin concentration must be maintained over $10 \mathrm{~g} / \mathrm{dL}$, and chelation must be stopped as soon as pregnancy is diagnosed. The most important factors to be assessed are cardiac function and iron load, using accurate MRI techniques. In cases of left ventricle-dysfunction development during gestation, and bearing in mind the maternal benefits and the potential fetal risks, DFO could be considered, especially after the critical period of organogenesis. Although CS subtracts from the additional stress of labor, it is usually limited to similar cases as in the general population, and time and mode of delivery should be individualized.

Further studies, as well as national and international registries for thalassemic pregnancies, should be organized and analyzed in order to establish guidelines for this important life period of the thalassemic woman.

\section{Disclosure}

The authors report no conflicts of interest in this work.

\section{References}

1. Weatherall DJ. The inherited diseases of hemoglobin are an emerging global health burden. Blood. 2010;115:4331-4336.

2. Craig JE, Rochette J, Fisher CA, et al. Dissecting the loci controlling fetal haemoglobin production on chromosomes $11 \mathrm{p}$ and $6 \mathrm{q}$ by the regressive approach. Nat Genet. 1996;12:58-64. 
3. Bauer DE, Orkin SH. Update on fetal hemoglobin gene regulation in hemoglobinopathies. Curr Opin Pediatr. 2011;23:1-8.

4. Old JM. Screening and genetic diagnosis of haemoglobin disorders. Blood Rev. 2003;17:43-53.

5. Cohen AR, Galanello R, Pennell DJ, Cunningham MJ, Vichinsky E. Thalassemia. Hematology Am Soc Hematol Educ Program. 2004;2004: 14-34.

6. Harteveld CL, Higgs DR. $\alpha$-Thalassaemia. Orphanet J Rare Dis. 2010; $5: 13$.

7. Vichinsky E. Complexity of alpha thalassemia: growing health problem with new approaches to screening, diagnosis, and therapy. Ann $N Y$ Acad Sci. 2010;1202:180-187.

8. Chui DH, Fucharoen S, Chan V. Hemoglobin H disease: not necessarily a benign disorder. Blood. 2003;101:791-800.

9. Higgs DR, Weatherall DJ. The alpha thalassaemias. Cell Mol Life Sci. 2009;66:1154-1162

10. Cao A, Galanello R. Beta-thalassemia. Genet Med. 2010;12:61-76.

11. Danjou F, Anni F, Galanello R. Beta-thalassemia: from genotype to phenotype. Haematologica. 2011;96:1573-1575.

12. Camaschella C, Cappellini MD. Thalassemia intermedia. Haematologica. 1995;80:58-68.

13. Rund D, Rachmilewitz E. Beta-thalassemia. N Engl J Med. 2005;353: 1135-1146.

14. Borgna-Pignatti C, Rugolotto S, De Stefano P, et al. Survival and complications in patients with thalassemia major treated with transfusion and deferoxamine. Haematologica. 2004;89:1187-1193.

15. Nassar AH, Usta IM, Rechdan JB, Koussa S, Inati A, Taher AT. Pregnancy in patients with $\beta$-thalassemia intermedia: outcome of mothers and newborns. Am J Hematol. 2006;81:499-502.

16. Toumba M, Kanaris C, Simamonian K, Skordis N. Outcome and management of pregnancy in women with thalassaemia in Cyprus. East Mediterr Health J. 2008;14:628-635.

17. Tuck SM. Fertility and pregnancy in thalassemia major. Ann N Y Acad Sci. 2005;1054:300-307.

18. Aessopos A, Karabatsos F, Farmakis D, et al. Pregnancy in patients with well-treated $\beta$-thalassemia: outcome for mothers and newborn infants. Am J Obstet Gynecol. 1999;180:360-365.

19. Daskalakis GJ, Papageorgiou IS, Antsaklis AJ, Michalas SK. Pregnancy and homozygous beta thalassaemia major. Br JObstet Gynaecol. 1998; 105:1028-1032.

20. Kumar RM, Rizk DE, Khuranna A. Beta-thalassemia major and successful pregnancy. J Reprod Med. 1997;74:127-131.

21. Tampakoudis P, Tsatalas C, Mamopoulos M, et al. Transfusiondependent homozygous $\beta$-thalassaemia major: successful pregnancy in five cases. Eur J Obstet Gynecol Reprod Biol. 1997;74:127-131.

22. Origa R, Piga A, Quarta G, et al. Pregnancy and $\beta$-thalassemia: an Italian multicenter experience. Haematologica. 2010;95:376-381.

23. Avila WS, Rossi EG, Ramires JA, et al. Pregnancy in patients with heart disease: experience with 1,000 cases. Clin Cardiol. 2003;26:135-142.

24. Voskaridou E, Balassopoulou A, Boutou E, et al. Pregnancy in $\beta$-thalassemia intermedia: 20-year experience of a Greek thalassemia center. Eur J Haematol. 2014;93:492-499.

25. De Sanctis V, Soliman AT, Elsedfy H, et al. Growth and endocrine disorders in thalassemia: the international network on endocrine complications in thalassemia (I-CET) position statement and guidelines. Indian J Endocrinol Metab. 2013;17:8-18.

26. De Sanctis V. Growth and puberty in thalassaemia. Horm Res. 2002;58: $72-79$.

27. Roussou P, Tsagarakis NJ, Kountouras D, Livadas S, DiamantiKandarakis E. $\beta$-Thalassemia major and female fertility: the role of iron and iron-induced oxidative stress. Anemia. 2013;2013:617204.

28. Agarwal A, Allamaneni S. Role of free radicals in female reproductive diseases and assisted reproduction. Reprod Biomed Online. 2004;9: 338-347.

29. Al-Gubory KH, Garrel C, Faure P, Sugino N. Roles of antioxidant enzymes in corpus luteum rescue from reactive oxygen species-induced oxidative stress. Reprod Biomed Online. 2012;25:551-560.
30. Mahachoklertwattana P, Yimsumruay T, Poomthavorn P, Chuansumrit A, Khlairit P. Acute effects of blood transfusion on growth hormone and insulin-like growth factor-1 levels in children with thalassemia. Horm Res Paediatr. 2011;75:240-245.

31. Soliman A, Yasin M, El-Awwa A, Osman M, De Sanctis V. Acute effects of blood transfusion on pituitary gonadal axis and sperm parameters in adolescents and young men with thalassemia major: a pilot study. Fertil Steril. 2012;98:638-643.

32. De Sanctis V, Elsedfy H, Soliman AT, et al. Acquired hypogonadotropic hypogonadism $(\mathrm{AHH})$ in thalassaemia major patients: an underdiagnosed condition? Mediterr J Hematol Infect Dis. 2016;8:e2016001.

33. Skordis N, Gourni M, Kanaris C, et al. The impact of iron overload and genotype on gonadal function in women with thalassaemia major. Pediatr Endocrinol Rev. 2004;2:292-295.

34. Chern JP, Lin KH, Tsai WY, et al. Hypogonadotropic hypogonadism and hematologic phenotype in patients with transfusion-dependent $\beta$-thalassemia. J Pediatr Hematol Oncol. 2003;25:880-884.

35. Kiess W, Reich A, Meyer K, et al. A role for leptin in sexual maturation and puberty? Horm Res.1999;51:55-63.

36. Perrone L, Perrotta S, Raimondo P, et al. Inappropriate leptin secretion in thalassaemia: a potential cofactor of pubertal timing derangement. J Pediatr Endocrinol Metab. 2003;16:877-881.

37. De Sanctis V, D'Ascola G, Wonke B. The development of diabetes mellitus and chronic liver disease in long term chelated $\beta$ thalassaemic patients. Postgrad Med J. 1986;62:831-836.

38. Humpeler E, Skrabal F, Bartsch G. Influence of exposure to moderate altitude on the plasma concentration of cortisol, aldosterone, renin, testosterone, and gonadotropins. Eur J Appl Physiol Occup Physiol. 1980;45: $167-176$.

39. Singer ST, Vichinsky EP, Gildengorin G, van Disseldorp J, Rosen M, Cedars MI. Reproductive capacity in iron overloaded women with thalassemia major. Blood. 2011;118:2878-2881.

40. Skordis N, Petrikkos L, Toumba M, et al. Update on fertility in thalassaemia major. Pediatr Endocrinol Rev. 2004;2:296-302.

41. Deech R. "A fine conception: the experience of the Human Fertilisation and Embryology Authority (HFEA)": speech to the 13th Congress of the European Association of Gynaecologists and Obstetricians (EAGO), Jerusalem, 11 May 1998. Eur J Obstet Gynecol Reprod Biol. 1999;85:3-5.

42. Smith V, Osianlis T, Vollenhoven B. Prevention of ovarian hyperstimulation syndrome: a review. Obstet Gynecol Int. 2015;2015:514159.

43. De Sanctis V, Perera D, Katz M, Fortini M, Gamberini MR. Spermatozoal DNA damage in patients with B thalassaemia syndromes. Pediatr Endocrinol Rev. 2008;6:185-189.

44. Perera D, Pizzey A, Campbell A, et al. Sperm DNA damage in potentially fertile homozygous $\beta$-thalassaemia patients with iron overload. Hum Reprod. 2002;17:1820-1825.

45. Singer ST, Vichinsky EP. Deferoxamine treatment during pregnancy: is it harmful? Am J Hematol. 1999;60:24-26.

46. Naik RP, Lanzkron S. Baby on board: what you need to know about pregnancy in the hemoglobinopathies. Hematology Am Soc Hematol Educ Program. 2012;2012:208-214.

47. Cousens NE, Gaff CL, Metcalfe SA, Delatycki MB. Carrier screening for $\beta$-thalassaemia: a review of international practice. Eur J Hum Genet. 2010;18:1077-1083.

48. Ladis V, Karagiorga-Lagana M, Tsatra I, Chouliaras G. Thirty-year experience in preventing haemoglobinopathies in Greece: achievements and potentials for optimisation. Eur J Haematol. 2013;90:313-322.

49. Loukopoulos D. Haemoglobinopathies in Greece: prevention programme over the past 35 years. Indian J Med Res. 2011;134:572-576.

50. Hussein N, Weng SF, Kai J, Kleijnen J, Qureshi N. Preconception risk assessment for thalassaemia, sickle cell disease, cystic fibrosis and Tay-Sachs disease. Cochrane Database Syst Rev. 2015;8:CD010849.

51. Phelan L, Bain BJ, Roper D, Jury C, Bain K. An analysis of relative costs and potential benefits of different policies for antenatal screening for $\beta$ thalassaemia trait and variant haemoglobins. J Clin Pathol. 1999; 52(9):697-700. 
52. Ou Z, Li Q, Liu W, Sun X. Elevated hemoglobin A2 as a marker for $\beta$-thalassemia trait in pregnant women. Tohoku J Exp Med. 2011;223: 223-226.

53. Benster B, Cauchi MN. Haemoglobin A2 level in pregnancy. J Clin Pathol. 1970;23:538-539.

54. Rosatelli MC, Tuveri T, Scalas MT, et al. Molecular screening and fetal diagnosis of $\beta$-thalassemia in the Italian population. Hum Genet. 1992;89:585-589.

55. Lau KT, Leung YT, Fung YT, Chan LW, Sahota DS, Leung NT. Outcome of 1,355 consecutive transabdominal chorionic villus samplings in 1,351 patients. Chin Med J (Engl). 2005;118:1675-1681.

56. Monni G, Ibba RM, Olla G, Rosatelli C, Cao A. Prenatal diagnosis of $\beta$-thalassaemia by second-trimester chorionic villus sampling. Prenat Diagn. 1988;8:447-451.

57. Pirastu M, Kan YW, Cao A, Conner BJ, Teplitz RL, Wallace RB. Prenatal diagnosis of $\beta$-thalassemia: detection of a single nucleotide mutation in DNA. N Engl J Med. 1983;309:284-287.

58. Kong CW, Leung TN, Leung TY, et al. Risk factors for procedurerelated fetal losses after mid-trimester genetic amniocentesis. Prenat Diagn. 2006;26:925-930.

59. Tabor A, Alfirevic Z. Update on procedure-related risks for prenatal diagnosis techniques. Fetal Diagn Ther. 2010;27:1-7.

60. Vrettou C, Palmer G, Kanavakis E, et al. A widely applicable strategy for single cell genotyping of $\beta$-thalassaemia mutations using DGGE analysis: application to preimplantation genetic diagnosis. Prenat Diagn. 1999;19:1209-1216.

61. Kokkali G, Traeger-Synodinos J, Vrettou C, et al. Blastocyst biopsy versus cleavage stage biopsy and blastocyst transfer for preimplantation genetic diagnosis of $\beta$-thalassaemia: a pilot study. Hum Reprod. 2007;22:1443-1449.

62. Sermon K. Current concepts in preimplantation genetic diagnosis (PGD): a molecular biologist's view. Hum Reprod Update. 2002;8:11-20.

63. Petrou M. Preimplantation genetic diagnosis. Hemoglobin. 2009;33: S7-S13.

64. Kuliev A, Pakhalchuk T, Verlinsky O, Rechitsky S. Preimplantation genetic diagnosis for hemoglobinopathies. Hemoglobin. 2011;35: 547-555.

65. Verlinsky Y, Rechitsky S, Sharapova T, Morris R, Taranissi M, Kuliev A. Preimplantation HLA testing. JAMA. 2004;291:2079-2085.

66. Wang W, Yap CH, Loh SF, et al. Simplified PGD of common determinants of haemoglobin Bart's hydrops fetalis syndrome using multiplexmicrosatellite PCR. Reprod Biomed Online. 2010;21:642-648.

67. Yap C, Tan AS, Wang W, Lim MN, Chong SS. First successful preimplantation genetic diagnosis in Singapore: avoidance of $\beta$-thalassaemia major. Ann Acad Med Singapore. 2009;38:720-723.

68. Lupton M, Oteng-Ntim E, Ayida G, et al. Cardiac disease in pregnancy. Curr Opin Obstet Gynecol. 2002;14:137-143.

69. Gardenghi S, Marongiu MF, Ramos P, et al. Ineffective erythropoiesis in $\beta$-thalassemia is characterized by increased iron absorption mediated by down-regulation of hepcidin and up-regulation of ferroportin. Blood. 2007;109:5027-5035.

70. Esposito BP, Breuer W, Sirankapracha P, et al. Labile plasma iron in iron overload: redox activity and susceptibility to chelation. Blood. 2003; 102:2670-2677.

71. Casanueva E, Viteri FE. Iron and oxidative stress in pregnancy. J Nutr. 2003;133:1700S-1708S.

72. Aessopos A, Berdoukas V, Tsironi M. The heart in transfusion dependent homozygous thalassaemia today: prediction, prevention and management. Eur J Haematol. 2008;80:93-106.

73. Aessopos A, Farmakis D. Pulmonary hypertension in $\beta$-thalassemia. Ann N Y Acad Sci. 2005;1054:342-349.

74. Mancuso A, Giacobbe A, De Vivo A, Ardita FV, Meo A. Pregnancy in patients with $\beta$-thalassaemia major: maternal and foetal outcome. Acta Haematol. 2008;119:15-17.

75. Aessopos A, Fragodimitri C, Karabatsos F, et al. Cardiac magnetic resonance imaging R2* assessments and analysis of historical parameters in patients with transfusion-dependent thalassemia. Haematologica. 2007;92:131-132.
76. Tanner MA, Galanello R, Dessi C, et al. Myocardial iron loading in patients with thalassemia major on desferrioxamine chelation. J Cardiovasc Magn Reson. 2006;8:543-547.

77. Kirk P, Roughton M, Porter JB, et al. Cardiac T2* magnetic resonance for prediction of cardiac complications in thalassemia major. Circulation. 2009;120:1961-1968.

78. Tsironi M, Karagiorga M, Aessopos A. Iron overload, cardiac and other factors affecting pregnancy in thalassemia major. Hemoglobin. 2010; $34: 240-250$.

79. Romero R. Intrauterine infection, premature birth and the fetal inflammatory response syndrome. J Nutr. 2003;133:1668S-1673S.

80. Walker EM, Walker SM. Effects of iron overload on the immune system. Ann Clin Lab Sci. 2000;30:354-365.

81. Pinero DJ, Hu J, Cook BM, et al. Interleukin-1 $\beta$ increases binding of the iron regulatory protein and the synthesis of ferritin by increasing the labile iron pool. Biochim Biophys Acta. 2000;1497:279-288.

82. Eleftheriou A, Kalakoutis G, Pavlides N. Transfusional transmitted viruses in pregnancy. J Pediatr Endocrinol Metab. 1998;11:901-914.

83. Davies JM, Lewis MP, Wimperis J, Rafi I, Ladhani S, Bolton-Maggs PH. Review of guidelines for the prevention and treatment of infection in patients with an absent or dysfunctional spleen: prepared on behalf of the British Committee for Standards in Haematology by a working party of the Haemato-Oncology Task Force. Br J Haematol. 2011;155:308-317.

84. Duryea E, Nicholson F, Cooper S, et al. The use of protease inhibitors in pregnancy: maternal and fetal considerations. Infect Dis Obstet Gynecol. 2015;2015:563727.

85. Steingrub J. Pregnancy-associated severe liver dysfunction. Crit Care Clin. 2004;20:763-776.

86. Olivieri NF, Brittenham GM. Iron-chelating therapy and the treatment of thalassemia. Blood. 1997;89:739-761.

87. St Pierre TG, Clark PR, Chua-Anusorn W, et al. Noninvasive measurement and imaging of liver iron concentrations using proton magnetic resonance. Blood. 2005;105:855-861.

88. Wood JC, Enriquez C, Ghugre N, et al. MRI R2 and R2* mapping accurately estimates hepatic iron concentration in transfusiondependent thalassemia and sickle cell disease patients. Blood. 2005; 106:1460-1465.

89. Royal College of Obstetricians and Gynaecologists. Management of Beta Thalasssaemia in Pregnancy. London: RCOG; 2014.

90. De Assis RA, Ribeiro AAF, Kay FU, et al. Pancreatic iron stores assessed by magnetic resonance imaging (MRI) in $\beta$ thalassemic patients. Eur J Radiol. 2012;81:1465-1470.

91. Spencer DH, Grossman BJ, Scott MG. Red cell transfusion decreases hemoglobin A1c in patients with diabetes. Clin Chem. 2011;57:344-346.

92. De Groot L, Abalovich M, Alexander EK, et al. Management of thyroid dysfunction during pregnancy and postpartum: an Endocrine Society clinical practice guideline. J Clin Endocrinol Metab. 2012;97: 2543-2565.

93. Jensen CE, Tuck SM, Agnew JE, et al. High incidence of osteoporosis in thalassaemia major. J Pediatr Endocrinol Metab. 1998;11:975-977.

94. Walsh JM, McGowan CA, Kilbane M, McKenna MJ, McAuliffe FM. The relationship between maternal and fetal vitamin D, insulin resistance, and fetal growth. Reprod Sci. 2013;20:536-541.

95. Tong $\mathrm{PC}, \mathrm{Ng} \mathrm{MC}, \mathrm{Ho} \mathrm{CS}$, et al. C-reactive protein and insulin resistance in subjects with thalassemia minor and a family history of diabetes. Diabetes Care. 2002;25:1480-1481.

96. Lao TT, Ho LF. $\alpha$-Thalassaemia trait and gestational diabetes mellitus in Hong Kong. Diabetologia. 2001;44:966-971.

97. White JM, Richards R, Byrne M, Buchanan T, White YS, Jelenski G. Thalassaemia trait and pregnancy. J Clin Pathol. 1985;38:810-817.

98. Tsatalas C, Chalkia P, Pantelidou D, Margaritis D, Bourikas G, Spanoudakis E. Pregnancy in $\beta$-thalassemia trait carriers: an uneventful journey. Hematology. 2009;14:301-303.

99. Savona-Ventura C, Grech ES. Pregnancy complications in homozygous thalassaemia patients. J Obstet Gynaecol. 1991;11:175-176.

100. Levy A, Fraser D, Katz M, et al. Maternal anemia during pregnancy is an independent risk factor for low birthweight and preterm delivery. Eur J Obstet Gynecol Reprod Biol. 2005;122:182-186. 
101. Singer ST, Wu V, Mignacca R, et al. Alloimmunization and erythrocyte autoimmunization in transfusion-dependent thalassemia patients of predominantly Asian descent. Blood. 2000;96:3369-3373.

102. Nassar AH, Naja M, Cesaretti C, et al. Pregnancy outcome in patients with $\beta$-thalassemia intermedia at two tertiary care centers, in Beirut and Milan. Haematologica. 2008;93:1586-1587.

103. Lialios G, Makrydimas G, Tsanadis G, Lolis D, Bourantas K. Effective treatment of $\beta$-thalassemia intermedia during pregnancy with rHuEpo: a case report. Minerva Ginecol. 2000;52:29-31.

104. Bennett M, Macri CJ, Bathgate SL. Erythropoietin use in a pregnant Jehovah's witness with anemia and $\beta$-thalassemia: a case report.

105. Thompson AA, Cunningham MJ, Singer ST, et al. Red cell alloimmunization in a diverse population of transfused patients with thalassaemia. Br J Haematol. 2011;153:121-128.

106. Kosaryan M, Mahdavi MR, Roshan P, et al. Prevalence of alloimmunisation in patients with $\beta$ thalassaemia major. Blood Transfus. 2012; 10:396-397.

107. Chou ST, Liem RI, Thompson AA. Challenges of alloimmunization in patients with haemoglobinopathies. Br J Haematol. 2012;159: 394-404.

108. Sau A, El-Matary A, Newton L, et al. Management of red cell alloimmunized pregnancies using conventional methods compared with that of middle cerebral artery peak systolic velocity. Acta Obstet Gynecol Scand. 2009;88:475-478.

109. Tsironi M, Ladis V, Margellis Z, Deftereos S, Kattamis C, Aessopos A Impairment of cardiac function in a successful full-term pregnancy in a homozygous $\beta$-thalassemia major: does chelation have a positive role? Eur J Obstet Gynecol Reprod Biol. 2005;120:117-118.

110. Yamada T, Grisham MB. Roll of neutrophil-derived oxidants in the pathogenesis of intestinal inflammation. Klin Wochenschr. 1991;69: 988-994.

111. Bosque MA, Domingo JL, Corbella J. Assessment of the developmental toxicity of deferoxamine in mice. Arch Toxicol. 1995;69: 467-471.

112. Curry SC, Bond GR, Raschke R, Tellez D, Wiggins D. An ovine model of maternal iron poisoning in pregnancy. Ann Emerg Med. 1990;19: 632-638.

113. Voskaridou E, Konstantopoulos K, Kyriakou D, Loukopoulos D. Deferoxamine treatment during early pregnancy: absence of teratogenicity in two cases. Haematologica. 1993;78:183-184.

114. Rachmilewitz EA, Giardina P. How I treat thalassemia. Blood. 2011;118: 3479-3488.

115. Bruin GJ, Faller T, Wiegand H, et al. Pharmacokinetics, distribution, metabolism, and excretion of deferasirox and its iron complex in rats. Drug Metab Dispos. 2008;36:2523-2538.

116. Vini D, Servos P, Drosou M. Normal pregnancy in a patient with $\beta$-thalassaemia major receiving iron chelation therapy with deferasirox $\left(\right.$ Exjade $\left.^{\circledR}\right)$. Eur J Hematol. 2011;86:274-275.

117. Diamantidis MD, Neokleous N, Agapidou A, et al. Iron chelation therapy of transfusion-dependent $\beta$-thalassemia during pregnancy in the era of novel drugs: is deferasirox toxic? Int J Hematol. 2016; 103(5):537-544.

118. Anderson LJ, Westwood MA, Holden S, et al. Myocardial iron clearance during reversal of siderotic cardiomyopathy with intravenous desferrioxamine: a prospective study using $\mathrm{T} 2 *$ cardiovascular magnetic resonance. Br J Haematol. 2004;127:348-355. J Reprod Med. 2005;50:135-137.

119. Davis BA, O'Sullivan C, Jarritt PH, Porter JB. Value of sequential monitoring of left ventricular ejection fraction in the management of thalassemia major. Blood. 2004;104:263-269.

120. Brenner B. Haemostatic changes in pregnancy. Thromb Res. 2004;114: 409-414.

121. James AH, Jamison MG, Brancazio LR, Myers ER. Venous thromboembolism during pregnancy and the postpartum period: incidence, risk factors, and mortality. Am J Obstet Gynecol. 2006;194:1311-1315.

122. Borgna Pignatti C, Carnelli V, Caruso V, et al. Thromboembolic events in $\beta$ thalassemia major: an Italian multicenter study. Acta Haematol. 1998;99:76-79.

123. Cappellini MD, Robbiolo L, Bottasso BM, Coppola R, Fiorelli G, Mannucci AP. Venous thromboembolism and hypercoagulability in splenectomized patients with thalassaemia intermedia. Br J Haematol. 2000;111:467-473.

124. Taher A, Isma'eel H, Mehio G, et al. Prevalence of thromboembolic events among 8,860 patients with thalassaemia major and intermedia in the Mediterranean area and Iran. Thromb Haemost. 2006;96:488-491.

125. Eldor A, Rachmilewitz EA. The hypercoagulable state in thalassemia Blood. 2002;99:36-43.

126. Bajoria R, Chatterjee R. Current perspectives of fertility and pregnancy in thalassemia. Hemoglobin. 2009;33:S131-S135.

127. Xu TT, Zhou F, Deng CY, et al. Low-dose aspirin for preventing preeclampsia and its complications: a meta-analysis. J Clin Hypertens (Greenwich). 2015;17:567-573.

128. Cappellini MD, Poggiali E, Taher AT, Musallam KM. Hypercoagulability in $\beta$-thalassemia: a status quo. Expert Rev Hematol. 2012;5: 505-512.

129. Nassar AH, Usta IM, Taher AM. $\beta$-Thalassemia intermedia and pregnancy: should we anticoagulate? J Thromb Haemost. 2006;4: 1413-1414.

130. [No authors listed]. Prevention of neural tube defects: results of the Medical Research Council Vitamin Study. Lancet. 1991;338:131-137.

131. Leung CF, Lao TT, Chang AM. Effect of folate supplement on pregnant women with $\beta$-thalassaemia minor. Eur J Obstet Gynecol Reprod Biol. 1989;33:209-213.

132. Orr D. Difficult intubation: a hazard in thalassaemia - a case report. Br J Anaesth. 1967;39:585-586.

133. Borgna-Pignatti C. Thalassemia: a few new tiles in a large mosaic. Haematologica. 2006;91:1159-1161.

134. Begley CM, Gyte GM, Devane D, McGuire W, Weeks A. Active versus expectant management for women in the third stage of labour. Cochrane Database Syst Rev. 2011:CD007412.

135. Lekawanvijit S, Chattipakorn N. Iron overload thalassemic cardiomyopathy: iron status assessment and mechanisms of mechanical and electrical disturbance due to iron toxicity. Can J Cardiol. 2009;25: 213-218.

136. Royal College of Obstetricians and Gynaecologists. Reducing the Risk of Thrombosis and Embolism during Pregnancy and the Puerperium. London: RCOG; 2015.

137. Ansari S, Azarkeivan A, Kivan AA, Tabaroki A. Pregnancy in patients treated for $\beta$ thalassemia major in two centers (Ali Asghar Children's Hospital and Thalassemia Clinic): outcome for mothers and newborn infants. Pediatr Hematol Oncol. 2006;23:33-37.

138. Leung TY, Lao TT. Thalassaemia in pregnancy. Best Pract Res Clin Obstet Gynaecol. 2012;26:37-51.

\section{Dovepress}

\section{Publish your work in this journal}

The International Journal of Women's Health is an international, peerreviewed open-access journal publishing original research, reports, editorials, reviews and commentaries on all aspects of women's healthcare including gynecology, obstetrics, and breast cancer. The manuscript management system is completely online and includes

a very quick and fair peer-review system, which is all easy to use. Visit http://www.dovepress.com/testimonials.php to read real quotes from published authors. 